\title{
Oropharyngeal candidiasis in head and neck cancer patients in Iran: Species identification, antifungal susceptibility and pathogenic characterization
}

\author{
Z. Jahanshiri a, ${ }^{\star}$, M. Shams-Ghahfarokhi ${ }^{b}$, M. Razzaghi-Abyaneh a \\ a Department of Mycology, Pasteur Institute of Iran, Tehran 13164, Iran \\ b Department of Mycology, Faculty of Medical Sciences, Tarbiat Modares University, Tehran, Iran
}

\section{Objective:}

Oropharyngeal candidiasis (OPC) is the most frequent opportunistic fungal infection in head and neck cancer patients [1]. This study was done to identify the Candida species which cause OPC and to evaluate their antifungal susceptibility pattern and pathogenic characteristics in Iranian head and neck cancer patients treated by radiotherapy.

\section{Methods:}

The oral clinical samples were determined by culturing on CHROMagar, carbohydrate assimilation and ITS sequencing methods. Biofilm formation, phospholipase and proteinase activity and antifungal susceptibility were examined too $[2,3]$.

\section{Resulats:}

Among 54 patients with confirmed OPC, 39 (72.22\%) patients were male and $15(27.77 \%)$ were female. The most frequently Candida species from a total of 60 isolates was $C$. albicans (53.3\%), followed by C. tropicalis (21.66\%), C. glabrata (15\%), C. kefyr (5\%) and C. dubliniensis (1.66\%) (Table 1). All the isolates were high-producers of biofilm in related of reference strain C. albicans ATCC 10231 (Figure 1). All of Candida isolates were proteinase positive and 47 isolates (81.04\%) represented phospholipase activity (Table 2). The maximum and minimum rates of antifungal resistance belonged to ketoconazole $(93.75 \%$ of C. albicans and $89.28 \%$ of Candida non-albicans) and fluconazole $(62.50 \%$ and $42.85 \%$ of C. albicans and Candida non-albicans) respectively (Table 3 ). The most effective antifungal against all candida isolates was fluconazole.

Table 3. Susceptibility and resistance percent of Candida isolates against antifungal agents are shown.

\begin{tabular}{lcccccc}
\hline \multirow{2}{*}{$\begin{array}{c}\text { Antifungal } \\
\text { agent }\end{array}$} & \multicolumn{3}{c}{ Candida albicans } & \multicolumn{3}{c}{ Candida non-albicans } \\
\cline { 2 - 7 } & MIC $(\mu \mathrm{g} / \mathrm{ml})$ & $\mathbf{S}(\%)$ & $\mathbf{R}(\%)$ & MIC $(\mu \mathrm{g} / \mathrm{ml})$ & $\mathbf{S}(\%)$ & $\mathbf{R}(\%)$ \\
\hline Fluconazole & $0.25-2.0$ & 37.5 & 62.50 & $0.25-0.5$ & 57.15 & 42.85 \\
Itraconazole & $0.0625-0.125$ & 18.75 & 81.25 & $0.0313-0.0125$ & 14.29 & 85.71 \\
Ketoconazole & $0.0625-0.125$ & 6.25 & 93.75 & $0.0625-0.125$ & 10.72 & 89.28 \\
Amphotericin B & $0.0625-0.25$ & 12.50 & 87.50 & $0.125-0.25$ & 30.72 & 69.28 \\
\hline
\end{tabular}

\section{Keywords:}

Oropharyngeal candidiasis, Head and neck cancer, Candida, Antifungal susceptibility.

\section{Conclusion:}

Our data can estimate abundance of OPC in male and female head and neck cancer patients and is helpful to use effective strategies for antifungal treatment, prophylaxis, and preventive therapies in these patients.

Table 1. Distribution of yeast species in relation to sex.

\begin{tabular}{lccc}
\hline \multicolumn{1}{c}{ Species } & Female & Male & Total \\
\hline C. albicans & $8(25 \%)$ & $24(75 \%)$ & 32 \\
C. tropicalis & $6(46.1 \%)$ & $7(53.8 \%)$ & 13 \\
C. glabrata & $2(22.2 \%)$ & $7(77.8 \%)$ & 9 \\
C. kefyr & -- & $3(100 \%)$ & 3 \\
C. dubliniensis & -- & $1(100 \%)$ & 1 \\
Pichia spp & -- & $2(100 \%)$ & 2 \\
\hline Total & $16(26.66 \%)$ & $44(73.33 \%)$ & $60(100 \%)$ \\
\hline
\end{tabular}

Table 2. Proteinase and phospholipase activity of the Candida spp. Strong activity $(++)$, moderate activity $(+)$ and no activity $(-)$.

\begin{tabular}{lcccccc}
\hline \multirow{2}{*}{$\begin{array}{l}\text { Candida species (number } \\
\text { of strains) }\end{array}$} & \multicolumn{3}{c}{$\begin{array}{c}\text { Proteinase } \\
\text { activity }\end{array}$} & \multicolumn{3}{c}{$\begin{array}{c}\text { Phospholipase } \\
\text { activity }\end{array}$} \\
\cline { 2 - 8 } C. albicans $(\mathrm{n}=32)$ & $\mathbf{+ +}$ & + & - & ++ & + & - \\
C. tropicalis $(\mathrm{n}=13)$ & 28 & 4 & 0 & 17 & 11 & 4 \\
C. glabrata $(\mathrm{n}=9)$ & 13 & 0 & 0 & 8 & 3 & 2 \\
C. kefyr $(\mathrm{n}=3)$ & 5 & 4 & 0 & 3 & 1 & 5 \\
C. dubliniensis $(\mathrm{n}=1)$ & 2 & 1 & 0 & 2 & 1 & 0 \\
& 0 & 1 & 0 & 0 & 1 & 0 \\
\hline
\end{tabular}

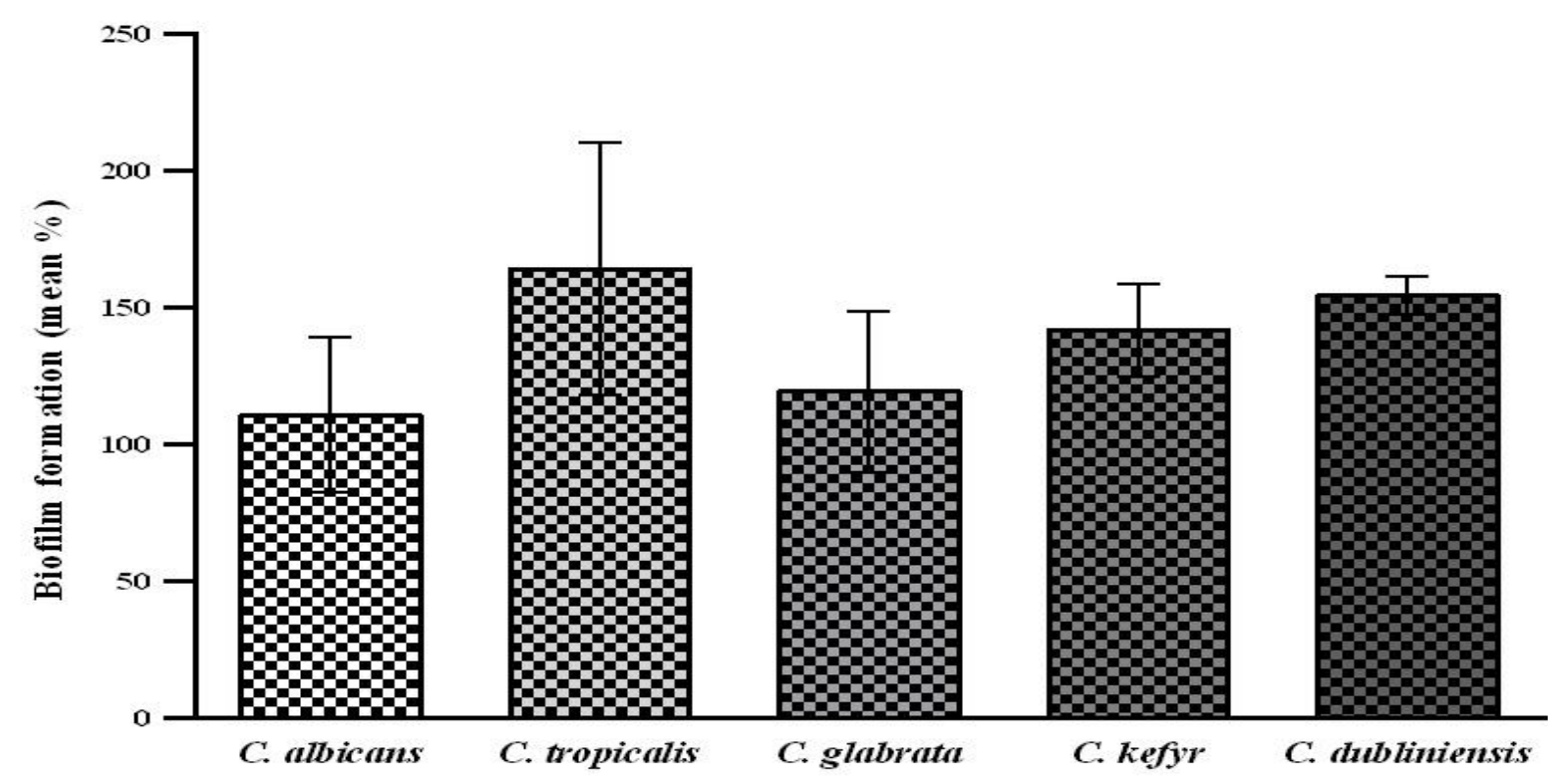

Figure 1. The mean of biofilm formation of five strains of clinical isolates in related of reference strain C. albicans ATCC10231 (100\%).

\section{References:}

1-Bensadoun R-J, Patton LL, Lalla RV, Epstein JB. Oropharyngeal candidiasis in head and neck cancer patients treated with radiation: update 2011. Support Care Cancer 2011; 19: 737-44

2-Pfaller M, Andes D, Diekema D, Espinel-Ingroff A, Sheehan D. Wild-type MIC distributions, epidemiological cutoff values and species-specific clinical breakpoints for Fluconazole and Candida: time for harmonization of CLSI and EUCAST broth microdilution methods. Drug Resist Updat 2010; 13: 180-95.

3-Jin Y, Yip H, Samaranayake Y, Yau J, Samaranayake L. Biofilm-forming ability of Candida albicans is unlikely to contribute to high levels of oral yeast carriage in cases of human immunodeficiency virus infection. J Clin Microbiol 2003; 41: 2961-7. 